\title{
Relative biological effectiveness in canine osteosarcoma cells irradiated with accelerated charged particles
}

\author{
JUNKO MAEDA $^{1}$, IAN M. CARTWRIGHT ${ }^{1}$, JEREMY S. HASKINS ${ }^{1}$, YOSHIHIRO FUJII ${ }^{2}$, \\ HIROSHI FUJISAWA ${ }^{3}$, HIROKAZU HIRAKAWA ${ }^{4}$, MITSURU UESAKA $^{3}$, HISASHI KITAMURA ${ }^{5}$, \\ AKIRA FUJIMORI $^{4}$, DOUGLAS H. THAMM ${ }^{6}$ and TAKAMITSU A. KATO ${ }^{1}$ \\ ${ }^{1}$ Department of Environmental \& Radiological Health Sciences, Colorado State University, Fort Collins, CO 80523, USA; \\ ${ }^{2}$ Department of Radiological Sciences, Ibaraki Prefectural University of Health Sciences, Inashiki, Ibaraki 300-0394; \\ ${ }^{3}$ School of Engineering, The University of Tokyo, Tokyo 113-8656; ${ }^{4}$ Research Center for Charged Particle Therapy, \\ International Open Laboratory; ${ }^{5}$ Research Development and Support Center, National Institute of Radiological Sciences, \\ Chiba 263-8555, Japan; ${ }^{6}$ Department of Clinical Sciences, Colorado State University, Fort Collins, CO 80523, USA
}

Received February 25, 2016; Accepted May 12, 2016

DOI: $10.3892 / \mathrm{ol} .2016 .4808$

\begin{abstract}
Heavy ions, characterized by high linear energy transfer (LET) radiation, have advantages compared with low LET protons and photons in their biological effects. The application of heavy ions within veterinary clinics requires additional background information to determine heavy ion efficacy. In the present study, comparison of the cell-killing effects of photons, protons and heavy ions was investigated in canine osteosarcoma (OSA) cells in vitro. A total of four canine OSA cell lines with various radiosensitivities were irradiated with ${ }^{137} \mathrm{Cs}$ gamma-rays, monoenergetic proton beams, $50 \mathrm{keV} / \mu \mathrm{m}$ carbon ion spread out Bragg peak beams and $200 \mathrm{keV} / \mu \mathrm{m}$ iron ion monoenergetic beams. Clonogenic survival was examined using colony-forming as says, and relative biological effectiveness (RBE) values were calculated relative to gamma-rays using the $D_{10}$ value, which is determined as the dose (Gy) resulting in $10 \%$ survival. For proton irradiation, the RBE values for all four cell lines were 1.0-1.1. For all four cell lines, exposure to carbon ions yielded a decreased cell survival compared with gamma-rays, with the RBE values ranging from 1.56-2.10. Iron ions yielded the lowest cell survival among tested radiation types, with RBE values ranging from 3.51-3.69 observed in the three radioresistant cell lines. The radiosensitive cell line investigated demonstrated similar cell survival for carbon and iron ion irradiation. The results of the present study suggest that heavy ions are more effective for killing radioresistant canine
\end{abstract}

Correspondence to: Professor Takamitsu A. Kato, Department of Environmental \& Radiological Health Sciences, Colorado State University, 1618 Campus Delivery, Fort Collins, CO 80523, USA E-mail: takamitsu.kato@colostate.edu

Key words: canine osteosarcoma, photon, carbon-ion, relative biological effectiveness
OSA cells when compared with gamma-rays and protons. This markedly increased efficiency of cell killing is an attractive reason for utilizing heavy ions for radioresistant canine OSA.

\section{Introduction}

Osteosarcoma (OSA) is the most common malignant bone cancer in dogs, representing $85 \%$ of canine skeletal neoplasms (1). OSA is a highly aggressive and painful tumor that occurs primarily in the appendicular skeleton of large and giant breed dogs (1). Treatment of OSA is difficult due to its high metastasis rate and aggressive local behavior (2). The current standard treatment for OSA in dogs is amputation or limb-sparing surgery combined with chemotherapy (2). Amputation or limb-sparing surgery is not always the choice of treatment for dogs with OSA due to neurologic or orthopedic disease (1). Alternative treatments to suppress tumor growth and alleviate the pain of the primary tumor would have significant clinical relevance in these cases. Coarsely fractionated, or 'palliative' radiation therapy using several fractioned doses (for example, 8-10 Gy per fraction) may be used for palliation of pain, but is not able to achieve local tumor control (3-5). High dose per fraction radiation therapy has been described as a method for local tumor control using stereotactic radiosurgery, particularly when combined with chemotherapy $(5,6)$. Stereotactic radiosurgery is able to deliver a single very high dose of radiation (for example, $30 \mathrm{~Gy}$ ) using multiple beams with a linear accelerator to a designated target, while sparing the surrounding tissues (6).

Charged particle radiation therapy, including proton and heavy ion therapy, has gained interest in human radiation oncology as a novel therapeutic modality (7). Clinical application of protons and carbon ions for human cancer treatment has been expanding and has achieved significantly improved clinical outcomes for a number of tumor types, including OSA in non-resectable tumors (8). Unlike conventional photon radiation, protons and carbon ions may be manipulated to 
release the majority of their energy only when they reach their target $(7,9)$. This property is known as the Bragg peak. Particle radiation therapy offers the possibility of a significantly increased dose of ionizing radiation to the tumor with very little dose deposited in the normal tissue (7-9). Particle radiation therapy has the potential to be considered as an alternative modality for the treatment of canine and human OSA in the future. Carbon ions have increased ionization density [high linear energy transfer (LET) properties], and heavy ions differ from protons or photons with low LET due to their radiobiological properties. A number of in vitro studies have demonstrated that high LET radiation is more effective than low LET radiation in terms of cell-killing effects (10-13). Additionally, the extent of cell killing by heavy ions is not cell cycle dependent and is not decreased due to the presence of hypoxia (14-16). In human oncology, the relative biological effectiveness $(\mathrm{RBE})$ is used to describe the increase in effectiveness of particle radiation $(10,12)$. RBE is defined as the ratio of doses of photons and charged particles inducing the same biological endpoints, including cell killing, mutation and cytogenetic aberrations. The RBE values of cell killing for heavy ions generally increases up to a LET near $200 \mathrm{keV} / \mu \mathrm{m}$ and decreases afterwards $(17,18)$.

Particle radiation therapy may be expensive to implement, and the application of heavy ions within veterinary clinics requires additional background information to determine its effectiveness. To the best of our knowledge, there are only limited reports of the use of protons for treating dogs with brain tumors and currently there have been no reports of using heavy ions to treat tumors in veterinary medicine $(19,20)$. RBE values of 1.96-2.50 in canine squamous cell carcinoma, fibrosarcoma and hemangiopericytoma cell lines for carbon ions (LET=108 keV/ $\mu \mathrm{m}$ ) have been previously reported (21). Our previous study described canine OSA cell lines that were either radioresistant or highly radiosensitive to photon radiation, along with their basic cellular characteristics (22). In the present study, an in vitro comparison of the cell-killing effects of photons, protons and heavy ions on canine OSA cells was performed. For heavy ion irradiation, SOBP (spread out Bragg peak) carbon ions (LET at $50 \mathrm{keV} / \mu \mathrm{m}$ ), which are used in radiotherapy, and iron ions (LET at $200 \mathrm{keV} / \mu \mathrm{m}$ ), as above are expected to have maximum biological effects of heavy ions (23).

\section{Materials and methods}

Cell culture. The canine OSA cell lines Abrams, D17, Grey and Moresco were a gift from the Animal Cancer Center of Colorado State University (Fort Collins, CO, USA) $(22,24)$. Cells were grown in minimal essential media (Invitrogen; Thermo Fisher Scientific, Inc., Waltham, MA, USA) supplemented with $10 \%$ (v/v) fetal bovine serum (FBS; Sigma-Aldrich, St. Louis, MO, USA) and 1\% (v/v) Pen/Strep and fungizone solution (Invitrogen; Thermo Fisher Scientific, Inc.), and they were maintained in a tissue culture incubator at $37^{\circ} \mathrm{C}$ in a $100 \%$ humidified atmosphere of $5 \% \mathrm{CO}_{2}$. The cell doubling times of these cells were $19 \mathrm{~h}$ for Abrams, $22 \mathrm{~h}$ for D17, $18 \mathrm{~h}$ for Grey and $22 \mathrm{~h}$ for Moresco (22).

Radiation conditions. Particle-based irradiation experiments were performed at the National Institute of Radiological
Sciences (NIRS) in Chiba, Japan. For heavy ion exposure, accelerated ions were irradiated using the Heavy Ion Medical Accelerator in Chiba (HIMAC; Chiba, Japan) at room temperature. The details concerning the beam characteristics of the particle radiation, biological irradiation procedures and dosimetry have been described previously $(12,25,26)$. Accelerated monoenergetic iron ions have $500 \mathrm{MeV} /$ nucleon of initial energy and $200 \mathrm{keV} / \mu \mathrm{m}$ of LET at the irradiated position. Carbon ions were accelerated at $290 \mathrm{MeV} /$ nucleon of initial energy and spread out with a ridge filter for $6 \mathrm{~cm}$ width of SOBP. The monolayer cell culture was irradiated at the center (50 keV/ $\mu \mathrm{m}$ of average LET) within the SOBP at a distance of $119 \mathrm{~mm}$ from the entrance (27). Monoenergetic protons that were accelerated to $70 \mathrm{MeV}$ using the NIRS-930 cyclotron have a LET value of 1.0 at the irradiated position. Dose rates for heavy ions and protons were set at 1 and $5 \mathrm{~Gy} / \mathrm{min}$ respectively. Gamma-ray irradiations were performed at the Colorado State University (Fort Collins, CO, USA) with ${ }^{137} \mathrm{Cs}$ gamma-rays delivered at a dose rate of $\sim 2.5 \mathrm{~Gy} / \mathrm{min}$ at room temperature (using a J.L. Shepherd Model Mark I-68, nominal $6000 \mathrm{Ci}{ }^{137} \mathrm{Cs}$ irradiator).

Cell survival assays. Exponentially growing cells cultured in T12.5 flasks (BD Biosciences, Franklin Lakes, NJ, USA) were irradiated, then trypsinized and plated onto $100 \mathrm{~mm}$ cell culture dishes at an density of 100 colonies. Following incubation for 7-10 days to allow colony formation, surviving colonies were rinsed with $0.9 \% \mathrm{NaCl}$, fixed with $100 \%$ ethanol and stained by $0.1 \%$ crystal violet. Each colony consisting of $>50$ cells was scored as a survivor. At least three independent experiments were performed.

RBE was calculated, which is defined as the ratio of dose of photons and charged particles inducing identical biological effects, based on $D_{10}$ values. The $D_{10}$ values, which represent doses required to achieve $10 \%$ survival, were obtained from each survival curve using Prism 5 software (GraphPad Software, Inc., La Jolla, CA, USA).

Statistical analysis. Data were analyzed using Prism 5 software. Data are presented as the mean \pm standard error. Differences with a $\mathrm{P}<0.05$ were considered statistically significant. Statistical comparison of mean values in the RBE was performed using unpaired two tailed t-test.

\section{Results}

The present study used canine OSA cell lines with various radiation sensitivities as reported previously (22). Abrams, D17 and Moresco were fairly resistant to gamma-rays $\left(D_{10}=7.12-9.33 \mathrm{~Gy}\right)$, while Grey was relatively radiosensitive $\left(D_{10}=2.72 \mathrm{~Gy}\right)$. Fig. 1 shows the dose-response curves for cell-killing effect on the four canine OSA cell lines irradiated with various radiation sources. It was observed that the clinically relevant carbon ion beams (LET at $50 \mathrm{keV} / \mu \mathrm{m}$ ) decreased cell survival fractions of the four canine OSA cell lines compared with gamma-rays $(\mathrm{P}<0.05)$. Iron ion beams decreased cell survival more than carbon ions in the three radioresistant cell lines (Abrams, D17 and Moresco). However, the radiosensitive cell line Grey demonstrated similar cell survival for both carbon and iron ion irradiation. The proton 
Table I. Relative biological effectiveness of particle radiation types in canine osteosarcoma cell lines.

\begin{tabular}{|c|c|c|c|c|c|c|c|}
\hline \multirow[b]{2}{*}{ Cell lines } & \multirow{2}{*}{$\frac{\begin{array}{c}\gamma \text {-rays, } \\
0.2 \mathrm{keV} / \mu \mathrm{m}\end{array}}{\mathrm{D}_{10}, \mathrm{~Gy}}$} & \multicolumn{2}{|c|}{$\begin{array}{l}\text { Proton, } \\
1 \mathrm{keV} / \mu \mathrm{m}\end{array}$} & \multicolumn{2}{|c|}{$\begin{array}{c}\text { Carbon SOBP, } \\
50 \mathrm{keV} / \mu \mathrm{m}\end{array}$} & \multicolumn{2}{|c|}{$\begin{array}{c}\text { Iron, } \\
200 \mathrm{keV} / \mu \mathrm{m}\end{array}$} \\
\hline & & $\mathrm{D}_{10}$, Gy & RBE & $\mathrm{D}_{10}$, Gy & RBE & $\mathrm{D}_{10}$, Gy & RBE \\
\hline Abrams & 7.12 & 3.96 & 1.80 & 3.81 & 1.87 & 2.01 & 3.55 \\
\hline D17 & 9.33 & 7.26 & 1.29 & 4.44 & 2.10 & 2.53 & 3.69 \\
\hline Grey & 2.72 & 3.02 & 0.90 & 1.55 & 1.75 & 1.23 & 2.22 \\
\hline Moresco & 7.24 & 6.68 & 1.08 & 4.64 & 1.56 & 2.62 & 3.51 \\
\hline
\end{tabular}

$D_{10}$ values represent doses required to achieve $10 \%$ survival. RBE was obtained from $\left(D_{10}\right.$ of $\gamma$-rays $) /\left(D_{10}\right.$ of particle irradiation $)$. SOBP, spread out Bragg peak beams; RBE, relative biological effectiveness.
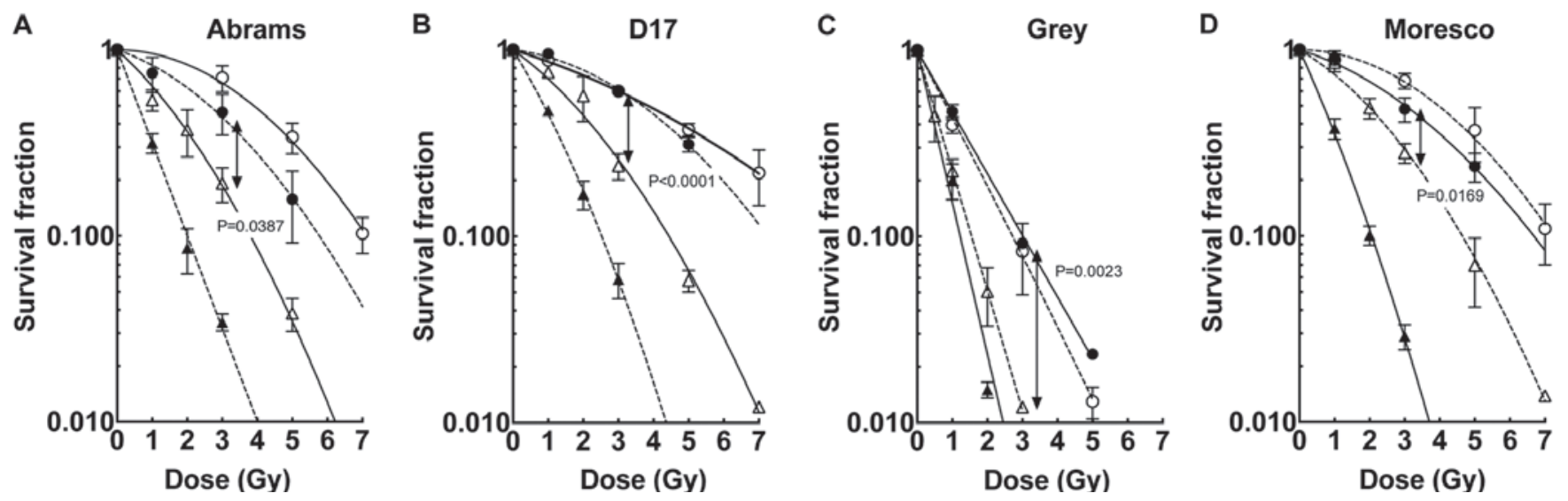

Figure 1. Survival curves for gamma-rays, proton and carbon ion irradiation in four canine osteosarcoma cell lines. White circle indicates gamma-rays, LET $0.2 \mathrm{keV} / \mu \mathrm{m}$; black circle indicates protons, LET $1 \mathrm{keV} / \mu \mathrm{m}$; white triangle indicates carbon ions, LET $50 \mathrm{keV} / \mu \mathrm{m}$; and black triangle indicates iron ions LET $200 \mathrm{keV} / \mu \mathrm{m}$. Experiments were performed at least three times and data are presented as the mean \pm standard error. LET, linear energy transfer.

cell survival curves demonstrated similar profiles to those of gamma-rays for the four cell lines. In order to describe the increased effects of particle radiation, RBE was calculated based on the $D_{10}$ values relative to gamma-rays (Fig. 2 and Table I). The RBE values ranged from $0.90-1.26$ for protons, 1.56-2.10 for carbon-ions and 2.22-3.69 for iron ions among the cell lines. The RBEs for iron ions in the radiosensitive Grey cell line (2.22) was reduced compared with those in the three radioresistant cell lines.

\section{Discussion}

The present study indicated that heavy ions may be a superior method to induce canine OSA cell killing in vitro compared with protons and gamma-rays, based on using four cell lines with various radiosensitivities. The results of the present study were consistent with a previous canine cell line study (21). Additionally, several other previous studies using human and rodent cells have demonstrated that high LET heavy ions are more effective for cell killing at identical physical absorbed doses as low LET radiation types $(10-12,21,26)$. In general, a large number of complex clusters of DNA damage generated by high LET radiation would be more difficult to repair, resulting in more severe biological damage than that induced by low LET radiation $(28,29)$.

\section{Relative biological effectiveness}

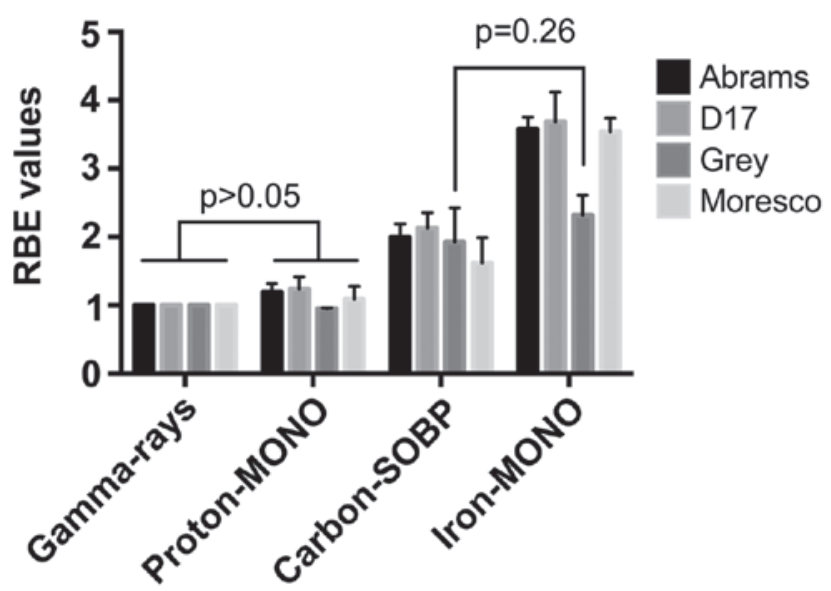

Figure 2. RBE values calculated from dose to get D10 survival fractions. The $\mathrm{RBE}$ values for protons (LET $1 \mathrm{keV} / \mu \mathrm{m}$ ), carbon ions (LET $50 \mathrm{keV} / \mu \mathrm{m}$ ) and iron ions (LET $200 \mathrm{keV} / \mu \mathrm{m}$ ) were obtained for each cell line relative to gamma-rays on each cell line. RBE, relative biological effectiveness; LET, linear energy transfer; SOBP, spread out Bragg peak beams; MONO, monoenergetic.

In the present study, the RBE values for the human clinical setting carbon ions ranged from 1.56-2.10 using $\mathrm{D}_{10}$ doses relative to that of gamma-rays. The $\mathrm{RBE}$ values of canine 
OSA cells for the carbon ions were close to the previously published values: $\sim 1.5$ for human salivary gland tumor origin HSG cells and 1.8 for HeLa cells, using identical carbon-ion beams (30). For a proton beam, which is another type of particle radiation with low LET, the cell killing effects did not differ substantially from gamma-rays, providing the RBE values of almost 1.0 for all four cell lines. In human oncology, the RBE of protons has been reported to exhibit experimental variations, but in general a constant RBE of either 1.0 or 1.1 is estimated for clinical applications (31-34). However not only LET, but also DNA repair capacity and cellular radiosensitivity affect RBE values $(7,26)$. The results of the present study suggest that the effectiveness of particle radiation on human and canine tumor cell killing is likely comparable.

Furthermore, the present results with regard to iron ion radiation clearly revealed that heavy ions with high LET $(200 \mathrm{keV} / \mu \mathrm{m})$ better enhanced the cell killing effects in radioresistant canine OSA cells compared with $50 \mathrm{keV} / \mu \mathrm{m}$ carbon ions. It should be noted that this is consistent with previous human and rodent studies, which observed the peak RBE is approximately LET $200 \mathrm{keV} / \mu \mathrm{m}(17,18)$. In the case of the radiosensitive cell line Grey, carbon and iron ion radiation demonstrated more similar cell killing effects and smaller RBE values compared to the radioresistant canine OSA cells. The response of Grey to high LET was similar to DNA-repair deficient cell lines in previous human and rodent studies $(26,35)$. Previous studies have suggested that high LET is effective to cells with normal cellular DNA repair capacity $(36,37)$. Furthermore, in a recent investigation, a variable response to radiation was detected clinically in dogs affected by OSA (38). Although it was beyond the scope of the present study, investigation into the DNA repair deficiencies of the radiosensitive OSA cell line may provide an insight into whether tumor cell radiosensitivity can be used as an indicator of clinical response to radiation therapy.

Canine OSA cells are considered to be resistant to conventional radiotherapy (1). In addition to improved dose distribution conferred by particle irradiation, a markedly increased efficiency of cell killing is another attractive reason for investigating heavy ions (15). Furthermore, hypoxic cells naturally occur within cancerous tissues. Hypoxic cells are resistant to low-LET photons, but may be effectively killed by high-LET heavy ions $(14,39)$. According to previous reports, it has been suggested that heavy ions may suppress the metastatic capabilities of cancer cells; thus, the effects of heavy ions on the control of lung metastasis of canine OSA should be investigated for clinical application $(40,41)$. Additional investigations are required to determine whether heavy ion radiotherapy is able to confer clinical advantages over photon irradiation in veterinary clinics, including in the treatment of dogs with OSA.

In conclusion, the results of the present study provide basic insights into the application of heavy ions in veterinary clinics. With the use of radioresistant and radiosensitive canine OSA cells, the present study demonstrated that high LET charged particles, particularly iron ions, are effective at killing canine OSA cells independent of gamma-ray radiosensitivity. Radioresistant and radiosensitive cells exhibited significantly higher RBE values for carbon and iron ion radiation $(\mathrm{P}<0.05 ;$ Fig. 2). These findings support the future investigation of heavy ion application within veterinary clinics to study their effectiveness compared with currently available radiation therapy.

\section{Acknowledgements}

The present research was funded by the College Research Council at Colorado State University College of Veterinary Medicine and Biosciences (TAK), the Dr. Akiko M. Ueno Radiobiology Fund (TAK) and the International Open Laboratory at the National Institute of Radiological Sciences (AF). The authors acknowledge support from NIRS-HIMAC and Cyclotron (Chiba, Japan).

\section{References}

1. Ehrhart NP, Ryan SD and Fan TM: Tumors of the skeletal system. In: Withrow and MacEwen's Small Animal Clinical Oncology. Withrow SJ, Vail DM and Page RL (eds). 5th edition. W.B. Saunders, St. Louis, MO, pp463-503, 2013.

2. Mueller F, Fuchs B and Kaser-Hotz B: Comparative biology of human and canine osteosarcoma. Anticancer Res 27: 155-164, 2007.

3. Ramirez O III, Dodge RK, Page RL, Price GS, Hauck ML, LaDue TA, Nutter F and Thrall DE: Palliative radiotherapy of appendicular osteosarcoma in 95 dogs. Vet Radiol Ultrasound 40: 517-522, 1999.

4. Green EM, Adams WM and Forrest LJ: Four fraction palliative radiotherapy for osteosarcoma in 24 dogs. J Am Anim Hosp Assoc 38: 445-451, 2002.

5. Coomer A, Farese J, Milner R, Liptak J, Bacon N and Lurie D: Radiation therapy for canine appendicular osteosarcoma. Vet Comp Oncol 7: 15-27, 2009.

6. Farese JP, Ashton J, Milner R, Ambrose LL and Van Gilder J: The effect of the bisphosphonate alendronate on viability of canine osteosarcoma cells in vitro. In Vitro Cell Dev Biol Anim 40: 113-117, 2004.

7. Schulz-Ertner D, Jäkel O and Schlegel W: Radiation therapy with charged particles. Semin Radiat Oncol 16: 249-259, 2006.

8. Schulz-Ertner D and Tsujii H: Particle radiation therapy using proton and heavier ion beams. J Clin Oncol 25: 953-964, 2007.

9. Tobias CA, Lyman JT, Chatterjee A, Howard J, Maccabee HD, Raju MR, Smith AR, Sperinde JM and Welch GP: Radiological physics characteristics of the extracted heavy ion beams of the bevatron. Science 174: 1131-1134, 1971.

10. Cox R, Thacker J, Goodhead DT and Munson RJ: Mutation and inactivation of mammalian cells by various ionising radiations. Nature 267: 425-427, 1977.

11. Eguchi-Kasai K, Murakami M, Itsukaichi H, Fukutsu K, Yatagai F, Kanai T, Ohara H and Sato K: Repair of DNA double-strand breaks and cell killing by charged particles. Adv Space Res 22: 543-549, 1998.

12. Suzuki M, Kase Y, Yamaguchi H, Kanai T and Ando K: Relative biological effectiveness for cell-killing effect on various human cell lines irradiated with heavy-ion medical accelerator in Chiba (HIMAC) carbon-ion beams. Int J Radiat Oncol Biol Phys 48: 241-250, 2000.

13. Fujisawa H, Genik PC, Kitamura H, Fujimori A, Uesaka M and Kato TA: Comparison of human chordoma cell-kill for $290 \mathrm{MeV} / \mathrm{n}$ carbon ions versus $70 \mathrm{MeV}$ protons in vitro. Radiat Oncol 8: 91, 2013.

14. Tobias CA, Blakely EA, Alpen EL, Castro JR, Ainsworth EJ, Curtis SB, Ngo FQ, Rodriguez A, Roots RJ, Tenforde T and Yang TC: Molecular and cellular radiobiology of heavy ions. Int J Radiat Oncol Biol Phys 8: 2109-2120, 1982.

15. Hamada N, Imaoka T, Masunaga S, Ogata T, Okayasu R, Takahashi A, Kato TA, Kobayashi Y, Ohnishi T, Ono K, et al: Recent advances in the biology of heavy-ion cancer therapy. J Radiat Res 51: 365-383, 2010.

16. Blakely EA, Tobias CA, Yang TC, Smith KC and Lyman JT: Inactivation of human kidney cells by high-energy monoenergetic heavy-ion beams. Radiat Res 80: 122-160, 1979.

17. Tsuruoka C, Suzuki M, Kanai T and Fujitaka K: LET and ion species dependence for cell killing in normal human skin fibroblasts. Radiat Res 163: 494-500, 2005. 
18. Kato TA, Tsuda A, Uesaka M, Fujimori A, Kamada T, Tsujii H and Okayasu R: In vitro characterization of cells derived from chordoma cell line U-CH1 following treatment with X-rays, heavy ions and chemotherapeutic drugs. Radiat Oncol 6: 116, 2011 .

19. Kaser-Hotz B, Sumova A, Lomax A, Schneider U, Klink B, Fidel $\mathrm{J}$ and Blattmann $\mathrm{H}$ : A comparison of normal tissue complication probability of brain for proton and photon therapy of canine nasal tumors. Vet Radiol Ultrasound 43: 480-486, 2002.

20. Bley CR, Sumova A, Roos M and Kaser-Hotz B: Irradiation of brain tumors in dogs with neurologic disease. J Vet Intern Med 19: 849-854, 2005.

21. Wada S, Van Khoa T, Kobayashi Y, Funayama T, Ogihara K, Ueno $\mathrm{S}$ and Ito N: Prediction of cellular radiosensitivity from DNA damage induced by gamma-rays and carbon ion irradiation in canine tumor cells. J Vet Med Sci 67: 1089-1095, 2005.

22. Maeda J, Yurkon CR, Fujisawa H, Kaneko M, Genet SC, Roybal EJ, Rota GW, Saffer ER, Rose BJ, Hanneman WH, et al: Genomic instability and telomere fusion of canine osteosarcoma cells. PLoS One 7: e43355, 2012.

23. Tsujii H, Mizoe J, Kamada T, Baba M, Tsuji H, Kato H, Kato S, Yamada S, Yasuda S, Ohno T et al: Clinical Results of Carbon Ion Radiotherapy at NIRS. J Radiat Res 48: S1-S13, 2007.

24. Legare ME, Bush J, Ashley AK, Kato T and Hanneman WH: Cellular and phenotypic characterization of canine osteosarcoma cell lines. J Cancer 2: 262-270, 2011.

25. Kamada T, Tsujii H, Tsuji H, Yanagi T, Mizoe JE, Miyamoto T, Kato H, Yamada S, Morita S, Yoshikawa K, et al; Working Group for the Bone and Soft Tissue Sarcomas: Efficacy and safety of carbon ion radiotherapy in bone and soft tissue sarcomas. J Clin Oncol 20: 4466-4471, 2002.

26. Cartwright IM, Bell JJ, Maeda J, Genet MD, Romero A, Fujii Y, Fujimori A, Kitamuta H, Kamada T, Chen DJ and Kato TA: Effects of targeted phosphorylation site mutations in the DNA-PKes phosphorylation domain on low and high LET radiation sensitivity. Oncol Lett 9: 1621-1627, 2015.

27. McMillan DD, Maeda J, Bell JJ, Genet MD, Phoonswadi G, Mann KA, Kraft SL, Kitamura H, Fujimori A, Yoshii Y, et al: Validation of $64 \mathrm{Cu}$-ATSM damaging DNA via high-LET Auger electron emission. J Radiat Res 56: 784-791, 2015.

28. Fakir H, Sachs RK, Stenerlöw B and Hofmann W: Clusters of DNA double-strand breaks induced by different doses of nitrogen ions for various LETs: Experimental measurements and theoretical analyses. Radiat Res 166: 917-927, 2006

29. Hada M and Georgakilas AG: Formation of clustered DNA damage after high-LET irradiation: A review. J Radiat Res 49: 203-210, 2008
30. Kanai T, Endo M, Minohara S, Miyahara N, Koyama-ito H, Tomura H, Matsufuji N, Futami Y, Fukumura A, Hiraoka T, et al: Biophysical characteristics of HIMAC clinical irradiation system for heavy-ion radiation therapy. Int J Radiat Oncol Biol Phys 44: 201-210, 1999.

31. Paganetti H, Niemierko A, Ancukiewicz M, Gerweck LE, Goitein M, Loeffler JS and Suit HD: Relative biological effectiveness (RBE) values for proton beam therapy. Int J Radiat Oncol Biol Phys 53: 407-421, 2002.

32. Carabe A, Moteabbed M, Depauw N, Schuemann J and Paganetti H: Range uncertainty in proton therapy due to variable biological effectiveness. Phys Med Biol 57: 1159-1172, 2012.

33. Tsunemoto H, Morita S, Ishikawa T, Furukawa S, Kawachi K, Kanai T, Ohara H, Kitagawa T and Inada T: Proton therapy in Japan. Radiat Res Suppl 8: S235-S243, 1985.

34. Wouters BG, Lam GK, Oelfke U, Gardey K, Durand RE and Skarsgard LD: Measurements of relative biological effectiveness of the $70 \mathrm{MeV}$ proton beam at TRIUMF using Chinese hamster V79 cells and the high-precision cell sorter assay. Radiat Res 146: 159-170, 1996.

35. Tobias CA, Blakely EA, Chang PY, Lommel L and Roots R: Response of sensitive human ataxia and resistant T-1 cell lines to accelerated heavy ions. Br J Cancer Suppl 6: 175-185, 1984.

36. Loucas BD and Geard CR: Kinetics of chromosome rejoining in normal human fibroblasts after exposure to low- and high-LET radiations. Radiat Res 138: 352-360, 1994.

37. George K, Wu H, Willingham V, Furusawa Y, Kawata T and Cucinotta FA: High- and low-LET induced chromosome damage in human lymphocytes: A time-course of aberrations in metaphase and interphase. Int J Radiat Biol 77: 175-183, 2001.

38. Walter CU, Dernell WS, LaRue SM, Lana SE, Lafferty MH, LaDue TA and Withrow SJ: Curative-intent radiation therapy as a treatment modality for appendicular and axial osteosarcoma: A preliminary retrospective evaluation of $14 \mathrm{dogs}$ with the disease. Vet Comp Oncol 3: 1-7, 2005.

39. Brurberg KG, Skogmo HK, Graff BA, Olsen DR and Rofstad EK: Fluctuations in pO2 in poorly and well-oxygenated spontaneous canine tumors before and during fractionated radiation therapy. Radiother Oncol 77: 220-226, 2005.

40. Ogata T, Teshima T, Kagawa K, Hishikawa Y, Takahashi Y, Kawaguchi A, Suzumoto Y, Nojima K, Furusawa Y and Matsuura N: Particle irradiation suppresses metastatic potential of cancer cells. Cancer Res 65: 113-120, 2005.

41. Akino Y, Teshima T, Kihara A, Kodera-Suzumoto Y, Inaoka M, Higashiyama S, Furusawa Y and Matsuura N: Carbon-ion beam irradiation effectively suppresses migration and invasion of human non-small-cell lung cancer cells. Int J Radiat Oncol Biol Phys 75: 475-481, 2009. 